\title{
Glucose Production in Pregnant Women at Term Gestation
}

\author{
SOURCES OF GLUCOSE FOR HUMAN FETUS
}

\author{
Satish C. Kalhan, Larry J. D’Angelo, Samuel M. Savin, and Peter A. J. Adam, \\ Division of Pediatric Metabolism, and Department of Reproductive Biology, Case \\ Western Reserve University School of Medicine at Cleveland Metropolitan \\ General Hospital, and Department of Earth Sciences, Case Western Reserve \\ University, Cleveland, Ohio 44109
}

\begin{abstract}
A B S T R A C T The effects of pregnancy and diabetes on systemic glucose production rates and the sources of glucose for the human fetus in utero were evaluated in five normal, four gestationally diabetic, and one insulin-dependent diabetic subject undergoing elective caesarean section at term gestation. Five normal nonpregnant women were studied for comparison. Systemic glucose production rates were measured with stable tracer $\left[1-{ }^{13} \mathrm{C}\right]$ glucose according to the primeconstant rate infusion technique. Even though the plasma glucose concentration during normal pregnancy had declined as compared with the nonpregnant subjects $(P<0.0005)$, the systemic glucose production rate was $16 \%$ greater, a rate sufficient to provide the glucose requirement of the fetus at term gestation. The decline in glucose concentration could be the result of an increase in apparent volume of distribution of glucose. Systemic glucose production rates in wellcontrolled, gestationally diabetic subjects were similar to those in normal pregnant subjects $(2.07 \pm 0.53$ vs. $2.42 \pm 0.51 \mathrm{mg} / \mathrm{kg} \cdot \mathrm{min})$. The sources of glucose for the human fetus at term gestation were evaluated by comparing $(a)$ natural variation in ${ }^{13} \mathrm{C}:{ }^{12} \mathrm{C}$ ratio of plasma glucose and $(b)$ enriched ${ }^{13} \mathrm{C}:{ }^{12} \mathrm{C}$ ratio of plasma glucose during $\left[1{ }^{13} \mathrm{C}\right]$ glucose infusion in maternal and fetal blood at delivery in both normal and diabetic subjects. These data showed that the fetal glucose pool was in equilibrium with the maternal glucose pool in both normal and diabetic subjects, indicating that a brief
\end{abstract}

\footnotetext{
A preliminary report of this work has been published as an abstract: Pediatr. Res. 1977. 11: 516. (Abstr.)

Dr. Kalhan is the recipient of the Research Investigator Award from the Diabetes Association of Greater Cleveland. Address reprint requests to Dr. Satish C. Kalhan, Department of Pediatrics, Cleveland Metropolitan General Hospital, 3395 Scranton Road, Cleveland, Ohio 44109.

Received for publication 25 May 1978 and in revised form 21 November 1978.
}

maternal fast did not initiate systemic glucose production in human fetus. A materno-fetal gradient was observed for betahydroxybutyrate.

\section{INTRODUCTION}

The increasing demands of the growing conceptus result in certain metabolic responses to calorie deprivation in the pregnant mother to provide a continuous supply of fuels for energy metabolism for both mother and fetus. This adaptation to food deprivation has been termed "accelerated starvation" of pregnancy by Frienkel et al. (1) and Felig (2). Briefly, the plasma glucose concentration declines, plasma free fatty acids and blood ketones rise, and the plasma amino acid concentration falls (3-6). A great deal of attention has been focused on the mechanism of hypoglycemia of fasting during pregnancy. There is a more rapid fall in plasma glucose concentration after food deprivation in both early and late gestation than there is in the nonpregnant state, even though the potential for gluconeogenesis from three carbon substrates is increased. The latter has been demonstrated by the rapid increase in plasma glucose concentration after intravenous alanine administration to 84-h fasted, pregnant human subjects early in gestation (4). Similarly, an enhanced capacity to convert alanine to glucose has been shown in in vivo and in vitro studies of pregnant rat liver preparations (7-9). The decline in glucose concentration has been attributed to the inability of the maternal glucose production to accelerate in response to increased requirements (2). In the present investigation we have measured the rates of glucose production in normal and diabetic pregnant subjects by tracer dilution technique, with the nonradioactive tracer $\left[1{ }^{13} \mathrm{C}\right]$ glucose.

During intrauterine life, the human fetus is completely dependent upon maternal supply of glucose 
and other fuels. Although the human newborn after birth can produce glucose to maintain his blood glucose concentration, it is unclear whether he produces glucose in utero, particularly during periods of maternal fasting. By comparing ${ }^{13} \mathrm{C}$ enrichment of maternal and fetal glucose with and without tracer infusion we have evaluated the sources of glucose for human fetus at term gestation in normal and diabetic subjects.

\section{METHODS}

Glucose production rates were measured in 10 pregnant women undergoing elective caesarean section for obstetric reasons between 36 and 40 wk gestation. Five subjects were normal, four were gestationally diabetic (GDM), ${ }^{1}$ and one had insulin-dependent diabetes (IDM). Their ages ranged from 18 to $38 \mathrm{yr}$. The GDM women and the IDM woman were obese, weight $>145-239 \%$ of ideal body wt. ${ }^{2}$ The normal subjects' weight ranged from 85 to $123 \%$ of ideal body wt. No evidence of toxemia including peripheral edema were observed in any subject. Gestational diabetes was diagnosed by an intravenous glucose $(25 \mathrm{~g})$ tolerance test administered during the third trimester of pregnancy. Their fractional disappearance rates of glucose were $0.6,0.66,1.0$, and $1.03 \%$ min. The GDM subjects were treated by dietary regulation and without insulin. They were placed on a 2,200-calorie diet distributed in three major meals and three snacks to maintain euglycemia throughout the day. Euglycemia was defined as fasting plasma glucose $<80 \mathrm{mg} / 100 \mathrm{ml}$ and a 2 -h postprandial glucose $<120 \mathrm{mg} / 100 \mathrm{ml}$. All diabetic subjects were hospitalized 3-4 d before elective caesarean section to insure optimal metabolic control. The IDM subject was treated with twice-daily injections of crystalline and neutral protamine Hagedorn insulin. Her fasting plasma glucose was maintained between 45 and $76 \mathrm{mg} / 100 \mathrm{ml}$. The morning dose of insulin was withheld on the day of surgery. Five normal, nonobese (78-110\% ideal body wt) nonpregnant women were also studied for comparison. The normal subjects had no family history of diabetes and were in good health. Written informed consent was obtained from each subject after fully explaining the procedure. Isotonic saline without glucose was administered during anesthesia and surgery to all pregnant women except one, who received lactated Ringer's solution for a brief period. The type of anesthesia (general or epidural), did not appear to have any effect on results. All subjects were studied $10-12 \mathrm{~h}$ after their last meal.

$\left[1-{ }^{13} \mathrm{C}\right]$ glucose with $88 \%{ }^{13} \mathrm{C}$ atom excess on Carbon-1 (C-1) was obtained from Merck Sharp \& Dohme of Canada Ltd. Dorval, Quebec, Canada. A weighed amount was dissolved in sterile isotonic saline for intravenous administration according to the prime-constant rate infusion technique $(10) .\left[1-{ }^{3} \mathrm{C}\right]-$ glucose was administered intravenously via a Holter pump (Extracorporeal Medical Specialities, Inc., King of Prussia, Pa.) in a superficial vein of the forearm at the rate of $3 \mu \mathrm{g} / \mathrm{kg}$ body $\mathrm{wt} \cdot \mathrm{min}$. The infusion in pregnant women was started $\cong 120$ min before the caesarean section. Blood samples were drawn at frequent intervals in heparinized syringes from an indwelling scalp-vein needle placed in a superficial vein of the opposite forearm. At delivery, simultaneous blood samples were obtained from the

${ }^{1}$ Abbreviations used in this paper: CA, cord arterial; CV, cord venous; GDM, gestationally diabetic; IDM, insulindependent diabetic; MV, maternal venous.

${ }^{2}$ Ideal body weight was calculated according to the Metropolitan Life Insurance Tables. 1970. Documenta Geigy. 711. maternal vein, cord artery, and the cord vein. The cord samples were obtained from an isolated clamped segment of the umbilical cord. The blood specimens were placed in chilled tubes immediately. Plasma was separated by centrifugation in cold temperature and stored at $-10^{\circ} \mathrm{C}$ for later analysis.

Isotopic discrimination is a common feature in biosynthetic processes in nature and results in different ${ }^{13} \mathrm{C}:{ }^{12} \mathrm{C}$ ratios in different classes of compounds within the same organism (11). In general, carbohydrates and proteins are enriched in ${ }^{13} \mathrm{C}$ relative to the lipid fractions. The low ${ }^{13} \mathrm{C}:{ }^{12} \mathrm{C}$ ratio of lipids has been shown to result from isotopic fractionation during the oxidation of pyruvate to acetyl coenzyme A (12). Very little information is available with regard to the effects of development and metabolic disorders on ${ }^{13} \mathrm{C}:{ }^{12} \mathrm{C}$ ratio of glucose in humans. We have previously shown that the naturally occurring ${ }^{13} \mathrm{C}:{ }^{12} \mathrm{C}$ ratio in plasma glucose in normal newborn infants at age $2 \mathrm{~h}$ is slightly higher than in normal adults and older infants (13). These differences in ${ }^{13} \mathrm{C}:{ }^{12} \mathrm{C}$ ratio could be the result of isotopic fractionation, or could reflect the result of different sources of glucose in the newborn infants (all endogenous) and in the older individual (exogenous and endogenous). If a similar difference between ${ }^{13} \mathrm{C}:{ }^{12} \mathrm{C}$ ratios of maternal and cord blood at birth were to occur, it might indicate initiation of glucose production in utero before delivery and birth. For this reason, the natural abundance of ${ }^{13} \mathrm{C}$ in plasma glucose was measured in simultaneously obtained maternal venous, cord arterial, and cord venous blood samples of five normal infants and five infants of IDM mothers. The normal subjects received only isotonic saline while the IDM mothers were treated with insulin and saline or insulin and glucose during labor and delivery.

Assays. Plasma glucose was measured by the glucoseoxidase method with a Beckman analyzer (Beckman Instruments, Inc., Fullerton, Calif.). $\left[1-{ }^{13} \mathrm{C}\right]$ glucose was analyzed by enzymatic decarboxylation in vacuum as described previously (14). The ${ }^{13} \mathrm{C}:{ }^{12} \mathrm{C}$ ratio of the carbon dioxide evolved from C-1 of glucose was measured with a magnetic deflection, double-collector mass spectrometer (Nuclide Corp., State College, Pa.). Corrections for blank, instrument background and tail, gas mixing, and ${ }^{12} \mathrm{C}^{16} \mathrm{O}^{17} \mathrm{O}$ contribution to mass 45 (predominantly ${ }^{13} \mathrm{C}^{16} \mathrm{O}^{16} \mathrm{O}$ ) were made according to the method of Craig (15). The ${ }^{13} \mathrm{C}$ enrichment of plasma glucose (equivalent to the specific activity) is reported in $\delta^{13} \mathrm{C}$ notation as the deviation in per mil (parts per thousand [\%०]) of the ${ }^{13} \mathrm{C}:{ }^{12} \mathrm{C}$ ratio from that of the PDB standard ${ }^{3}$ as follows: $\delta^{13} \mathrm{C}=\left(\left[{ }^{13} \mathrm{C}:{ }^{12} \mathrm{C}\right.\right.$ sample $-{ }^{13} \mathrm{C}:{ }^{12} \mathrm{C}$ standard $] /{ }^{13} \mathrm{C}:{ }^{12} \mathrm{C}$ standard $)$ $\times 1,000$. The precision of measuring $\delta^{13} \mathrm{C}$ by mass spectrometer is $\pm 0.1 \%$. Systemic glucose production rate was calculated from the dilution of the infused tracer in the plasma as determined by the change in ${ }^{13} \mathrm{C}$ abundance of $\mathrm{C}-1$ of glucose from the basal to the enriched steady-state value. We have described the analytical details and the calculations in a previous publication (14). Plasma D-betahydroxybutyrate concentration were measured by enzymatic fluorometric method as described by Persson (17). Plasma insulin was measured according to the coated-charcoal immunoassay of Herbert et al. with porcine insulin standard (18). Paired $t$ test was employed for statistical analysis.

\section{RESULTS}

Plasma glucose and glucose production rate in pregnancy (Fig. 1, Table I). The plasma glucose concen-

${ }^{3}$ The PDB standard is a Cretaceous belemnite, Belemnitella americana, from the Pee Dee Formation of South Carolina (16) and is used widely as a reference standard for studies of geological variations in ${ }^{13} \mathrm{C}:{ }^{12} \mathrm{C}$ ratio. 

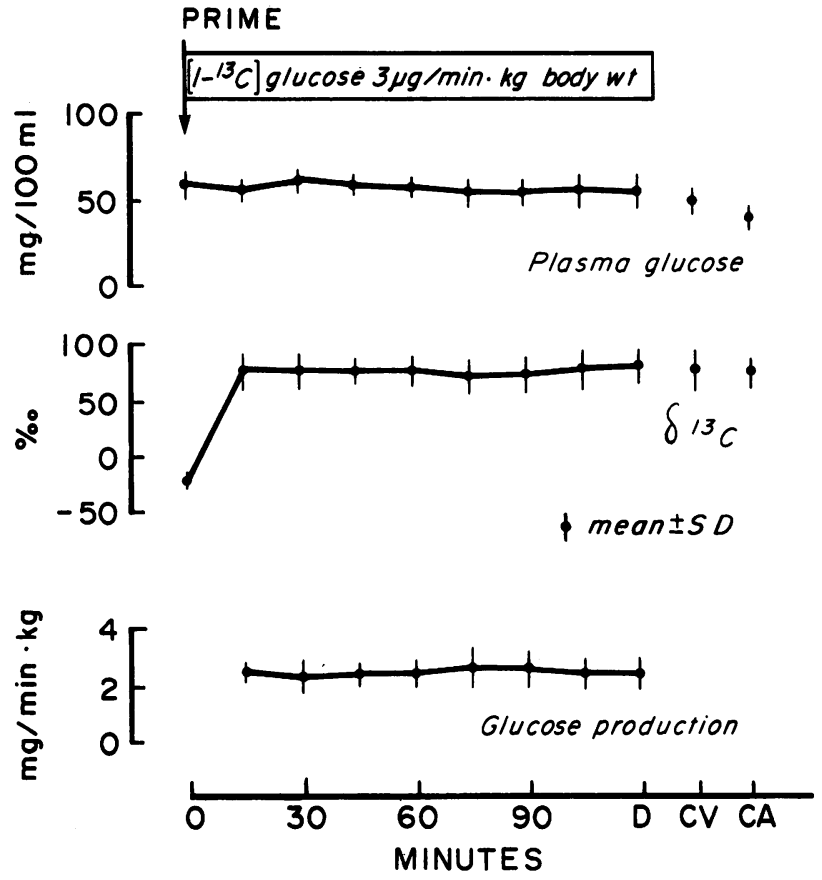

FIGURE 1 Glucose production in five normal women at term gestation. After a prime injection of $270 \mu \mathrm{g} / \mathrm{kg},\left[1-{ }^{13} \mathrm{C}\right] \mathrm{glucose}$ was infused at a constant rate of $3 \mu \mathrm{g} / \mathrm{min} \cdot \mathrm{kg}$ body wt. Blood samples were drawn at 15 -min intervals until delivery (D). Plasma glucose concentration, ${ }^{13} \mathrm{C}$ enrichment of $\mathrm{C}-1$ of glucose $\left(\delta^{13} \mathrm{C}\right)$, and glucose production rates are displayed. $\mathrm{CV}$, cord vein; CA, cord artery. Values are mean \pm SD.

tration after a 12-h fast in normal pregnant women at term gestation was $58 \pm 6.1 \mathrm{mg} / 100 \mathrm{ml}($ mean $\pm \mathrm{SD})$. It was higher and more variable in the GDM women $68 \pm 17.5$. In the IDM subject, blood glucose varied between 100 and $80 \mathrm{mg} / 100 \mathrm{ml}$. There was a sharp decline in her plasma glucose and a rise in the ${ }^{13} \mathrm{C}$ enrichment of glucose during anesthesia and delivery. Her glucose production rate was calculated during steady-state before this alteration in glucose and $\delta^{13} \mathrm{C}$.

TABLE I

Plasma Glucose and Systemic Glucose Production Rate in Pregnancy

\begin{tabular}{lccc}
\hline & & \multicolumn{2}{c}{ Glucose production rate } \\
\cline { 3 - 4 } & Glucose & $\begin{array}{c}\text { Present } \\
\text { weight }\end{array}$ & $\begin{array}{c}\text { Prepregnancy } \\
\text { weight }\end{array}$ \\
\hline & $m g / 100 \mathrm{ml}$ & \multicolumn{2}{c}{$\mathrm{mg} / \mathrm{kg} \cdot \mathrm{min}$} \\
Normals $(n=5)$ & $58 \pm 6.1^{*}$ & $2.42 \pm 0.51$ & $2.8 \pm 0.59$ \\
GDM $(n=4)$ & $68 \pm 17.5$ & $2.07 \pm 0.53$ & $2.28 \pm 0.65$ \\
IDM $(n=1)$ & 100 & 3.83 & 4.98 \\
Nonpregnant women & & & \\
$(n=5)$ & $78 \pm 4.6$ & $2.43 \pm 0.61$ & \\
\hline
\end{tabular}

$*$ Mean \pm SD.
As has been observed by others previously (19), the glucose concentration during normal pregnancy is lower than that observed in nonpregnant females (Table I). This decline in glucose concentration has been attributed to the failure of maternal glucose production to accelerate in the presence of increased metabolic demands. Systemic glucose production rates were measured by the prime-constant rate infusion technique with the nonradioactive ${ }^{13} \mathrm{C}$-labeled glucose. As most of the label randomizes away from C-1 of glucose during recycling $(20,21)$, and the enzymatic assay evolves $\mathrm{CO}_{2}$ from $\mathrm{C}-1$ glucose, the contribution of recycling to the estimation of glucose production rate was minimal. As shown in Fig. 1, a steadystate plasma glucose ${ }^{13} \mathrm{C}$ enrichment $\left(\delta^{13} \mathrm{C}\right)$ was achieved within 15 min of infusion and was maintained until delivery. Anesthesia and delivery did not cause any pertubation in the ${ }^{13} \mathrm{C}$ enrichment in any subject except the IDM woman. In normal mothers, the glucose production rate was $2.42 \pm 0.51 \mathrm{mg} / \mathrm{min} \cdot \mathrm{kg}$ body wt. The normoglycemic GDM mothers had a systemic glucose production rate of $2.07 \pm 0.53 \mathrm{mg} / \mathrm{kg} \cdot \mathrm{min}$. These rates were not significantly different from each other, nor from the glucose production rates in nonpregnant subjects $(2.43 \pm 0.61)$. The glucose production rate in the IDM subject was one and one-half times that of the normals $(3.83 \mathrm{mg} / \mathrm{kg} \cdot \mathrm{min})$.

\section{Sources of fuels for the human fetus at term gestation}

\section{GLuCose}

The glucose concentration in the cord arterial (CA) and the cord venous (CV) blood was lower than the maternal venous (MV) blood in normal, GDM, and IDM mothers (Figs. 2 and 3). The MV-CV difference was insignificant in the normoglycemic mothers, while a greater difference was observed in the hyperglycemic mothers. The CA glucose concentration was significantly lower than MV glucose concentration in both normal and diabetic mothers. Similarly, a significant CV-CA gradient for glucose was seen in all groups studied. These data suggest a transfer of glucose from the mother to the fetus along a concentration gradient; however, a fetal glucose source cannot be identified. For this reason, the $\delta^{13} \mathrm{C}$ of $\mathrm{MV}, \mathrm{CV}$, and CA glucose was compared during $(a)$ an unenriched steady-state occurring naturally (Fig. 3), and (b) an enriched steady-state achieved by infusing $\left[\mathrm{i}^{13} \mathrm{C}\right]$ glucose to the mother (Fig. 2).

Natural variation in $\delta^{13} \mathrm{C}$ in maternal and fetal blood (Fig. 3). Even though the ${ }^{13} \mathrm{C}$ enrichment of a 2-h-old infant's blood glucose tends to be greater than that of the mother (9), the ${ }^{13} \mathrm{C}$ enrichment of $\mathrm{CV}$ glucose closely resembles that of the mother, irrespective of 


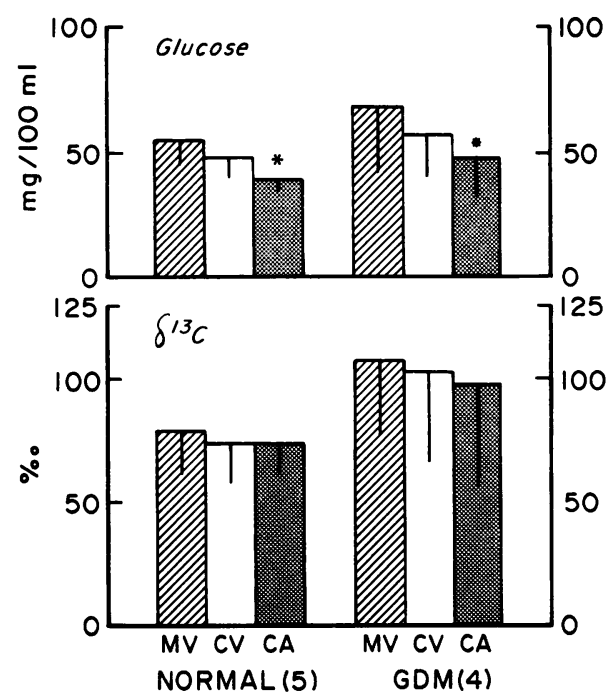

Figure 2 Plasma glucose and glucose ${ }^{13} \mathrm{C}$ enrichment $\left(\delta^{13} \mathrm{C}\right)$ during $\left[1-{ }^{13} \mathrm{C}\right]$ glucose infusion in maternal and cord blood. $\left[1^{-13} \mathrm{C}\right]$ glucose was infused as in Fig. $1 . \mathrm{CV}$, cord vein; CA, cord artery; MV, maternal vein. Values are mean \pm SD. ${ }^{*}$ Paired analysis of MV vs. CA, $P<0.01$. " Paired analysis of MV vs. $\mathrm{CA}, P<0.05$.

maternal glucose concentration. Although there was no statistically significant difference between maternal and fetal ${ }^{13} \mathrm{C}$ abundances, the $\delta^{13} \mathrm{C}$ of $\mathrm{CA}$ glucose was slightly greater than that of mothers $(P>0.1)$. These
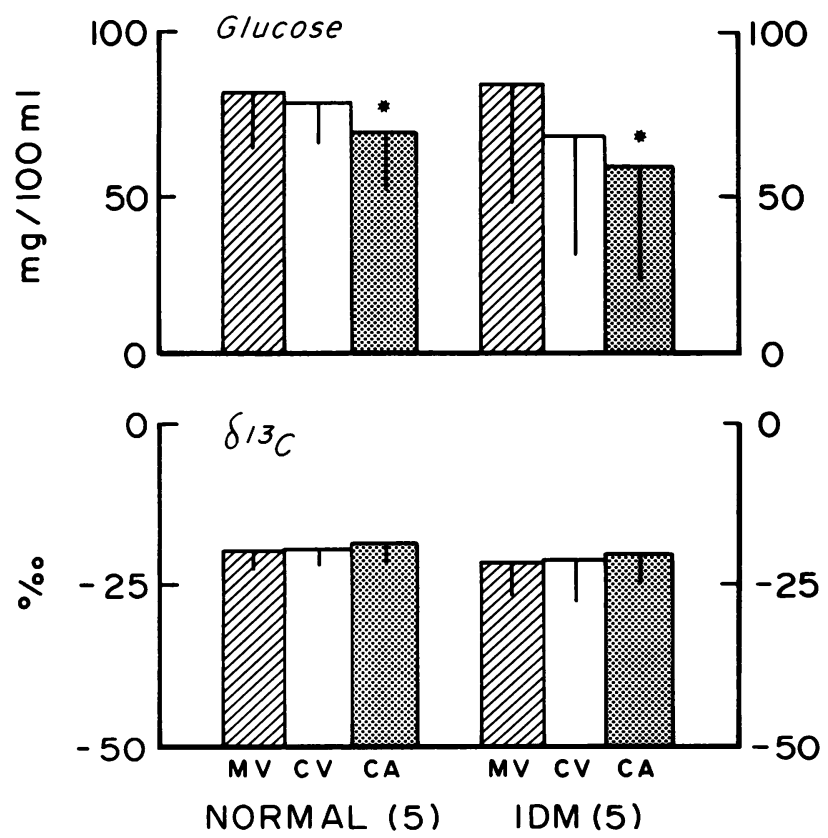

Figure 3 Plasma glucose and natural variation in $\delta^{13} \mathrm{C}$ in maternal and cord blood glucose in normal and IDM mothers. $\mathrm{CV}$, cord vein; CA, cord artery; MV, maternal vein. Values are mean $\pm \mathrm{SE}$. ${ }^{\star}$ Paired analysis of $\mathrm{MV}$ vs. CA, $P<0.01$. data suggest an isotopic fractionation or exchange during fetal glucose metabolism, or a maximal $10 \%$ fetal contribution to the fetal glucose pool.

Maternal and fetal glucose $\delta^{13} \mathrm{C}$ during $\left[1^{-13} \mathrm{C}\right]$ glucose infusion. The ${ }^{13} \mathrm{C}$ enrichments of $\mathrm{MV}$ and $\mathrm{CV}$ glucose during $\left[1-{ }^{13} \mathrm{C}\right]$ glucose infusion were similar in normal and GDM mothers (Fig. 2). The IDM mother also showed similar results ( $\delta^{13} \mathrm{C}$ MV: $63.6 \%$; CV: $65.9 \%$ ). These data, which are in contrast with the studies in pregnant rats $(22,23)$, indicate that the fetal glucose pool is in equilibrium with the maternal glucose pool, and that maternal glucose is the only source of glucose for the human fetus at term gestation after a brief overnight fast.

\section{BETAHYDROXYBUTYRATE (TABLE II)}

After a brief fast, the plasma concentration of betahydroxybutyrate had increased fivefold in pregnant mothers as compared with nonpregnant subjects. There was no difference in the betahydroxybutyrate concentration in normal and GDM mothers. A gradient along which betahydroxybutyrate is transferred from the mother to fetus was evident when MV and CV concentrations were compared: the $\mathrm{CV}$ and $\mathrm{CA}$ concentrations were significantly lower than $\mathrm{MV}$ concentration $(P<0.01)$.

Plasma insulin (Table III). The plasma insulin con-

TABLE II

Betahydroxybutyrate Concentration in Maternal and Cord Blood at Delivery

\begin{tabular}{llll}
\hline $\mathrm{MV}$ & $\mathrm{CV}$ & $\mathrm{CA}$ \\
\hline$m M$ & $m M$ & $m M$
\end{tabular}

\begin{tabular}{lccc} 
Normals & & & \\
1 & 0.20 & 0.04 & 0.013 \\
2 & 0.36 & 0.12 & 0.09 \\
3 & 0.70 & 0.44 & 0.27 \\
4 & 0.49 & 0.17 & 0.13 \\
5 & 0.92 & 0.45 & 0.27 \\
Mean \pm SD & $0.53 \pm 0.28$ & $0.24 \pm 0.19^{*}$ & $0.16 \pm 0.11^{*}$ \\
GDM & & & \\
1 & 0.25 & 0.22 & 0.06 \\
2 & 0.84 & 0.32 & 0.25 \\
3 & 0.55 & 0.21 & 0.21 \\
4 & 0.47 & 0.16 & 0.11 \\
Mean \pm SD & $0.53 \pm 0.24$ & $0.23 \pm 0.07 \ddagger$ & $0.16 \pm 0.09^{*}$ \\
IDM & 0.49 & 0.25 & - \\
Nonpregnant & & & \\
women $(n=5)$ & $0.14 \pm 0.05$ & & \\
\hline
\end{tabular}

* Significantly different by paired $t$ test $P<0.01$ as compared with MV levels.

$\ddagger$ Significantly different by paired $t$ test $P<0.05$ as compared with MV levels. 
TABLE III

Plasma Insulin Concentration in Maternal and Cord Blood at Delivery

\begin{tabular}{lccc}
\hline & $\mathrm{MV}$ & $\mathrm{CV}$ & $\mathrm{CA}$ \\
\hline & $\mu U / m l$ & $\mu U / m l$ & $\mu U / m l$ \\
Normals $(n=5)$ & $6.8 \pm 4.6^{*}$ & $7.2 \pm 2.4$ & $8.3 \pm 4.7$ \\
GDM $(n=4)$ & $19.2 \pm 10.5$ & $20.0 \pm 5.9$ & $22.5 \pm 8.7$ \\
$\begin{array}{l}\text { Nonpregnant women } \\
(n=5)\end{array}$ & $7.9 \pm 3.1$ & & \\
\hline
\end{tabular}

* Mean \pm SD.

centrations in normal pregnant and nonpregnant subjects were similar. The GDM subjects had three times higher insulin concentration than normal pregnant subjects $(19.2 \pm 10.5$ vs. $6.8 \pm 4.6 \mu \mathrm{U} / \mathrm{ml})$, perhaps as a result of obesity and intermittent maternal hyperglycemia. The CA and CV insulin were also higher in the GDM subjects, which reflects intermittent fetal hyperglycemia.

\section{DISCUSSION}

The postabsorptive decline in the maternal blood glucose concentration in pregnancy has been attributed to the continuous use by the growing fetus who consumes glucose as the major fuel for his energy requirement (24). The decline in glucose is associated with a decrease in blood concentration of amino acids both in early and late human pregnancy $(4,5)$. A similar decline in glucogenic amino acids during fasting has been observed in rats and subhuman primates in late pregnancy $(6,25)$. Despite a decline in plasma glucogenic amino acids concentration, the urinary urea and total nitrogen excretion during starvation (in early gestation in human, and late gestation in rats) is either equal to or more than in the nonpregnant state $(2,7)$. These data suggest that gluconeogenesis from amino acids is maintained at the same rate as in the nonpregnant state. Furthermore, the capacity to convert alanine to glucose by the liver in pregnancy is increased (1). In human studies, administration of a large bolus of alanine to pregnant women after an 85-h fast early in gestation results in rapid increase in plasma glucose (4). Although a similar rise in blood glucose after a bolus alanine administration was observed by Wise et al. (26) at term gestation, a gluconeogenic effect could not be distinguished from a glycogenolytic effect in the latter study. An increased rate of conversion of alanine and pyruvate to glucose has been shown in isolated liver preparation from pregnant rats as well as in intact pregnant rats by Herrera et al. (7) and Metzger et al. (8). Thus, during pregnancy, a paradox exists in that in the presence of increased gluconeogenic potential and a normal or increased rate of gluconeogenesis, as assessed by urinary nitrogen excretion, there is a decline in plasma glucose.

Systemic glucose production rates have not been quantified before in human pregnancy. With the nonradioactive, stable isotope-labeled tracer, we have measured the rates of glucose production in pregnant mothers. As indicated, the rates of glucose production during pregnancy in normal mothers were similar to nonpregnant adults if expressed per unit body weight. The pregnant mother, however, has increased her weight by $\cong 15-20 \%$. Most of the weight gain is not represented by the fetus with his high glucose consumption. Therefore, the data have been expressed based upon prepregnancy weight in Table I. In normal pregnant women, the rate of glucose production, when related to prepregnancy weight, was $16 \%$ higher than would be expected in the nonpregnant subject. Such an increase would be sufficient to provide the glucose at the rate of $5-6 \mathrm{mg} / \mathrm{kg} \cdot \mathrm{min}$ to the fetus at term gestation. These rates exceed the rates of glucose production measured in the human newborn by the tracer dilution technique at 2 -h of age, when $50 \%$ of the calorie needs are provided by glucose $(13,27)$, and approach the production rates measured in newborn infants after termination of continuous glucose infusions (28). A similar increased rate of glucose production was observed in late gestation ( $20 \mathrm{~d}$ ) by Metzger et al. in fasting pregnant rats with $\left[6-{ }^{14} \mathrm{C}\right]$ glucose as tracer $(29)$. Under steadystate conditions, glucose turnover in 48-h fasted, pregnant rats was $71 \%$ greater as compared with similarly fasted, age-matched virgin rats. Thus, despite an apparent increase in glucose production rate, the plasma glucose concentration was lower in the pregnant group than in the nonpregnant subjects.

Such a decline in glucose could be the result of increased distribution space. A strict comparison of distribution volume is not possible from our data because we did not study the same subjects post partum. An increased volume of distribution can be inferred by comparing the turnover data in pregnant and nonpregnant subjects; that is, under steady-state condition with equal rate of glucose production and use, the only way the glucose concentration could decline in the extracellular compartment would be by an increase in the volume of this compartment. A similar inference can be drawn from the serial intravenous glucose tolerance test done in late pregnancy and post partum by Bleicher et al. (30). Calculation of apparent volume of distribution by extrapolation of the glucose disappearance curve in their subject showed that the post partum increase in glucose concentration was associated with a decrease in the distribution volume, while the total glucose pool remained unchanged.

Thus it can be concluded that the human subjects, during pregnancy, accelerate the systemic glucose production rate to meet the increasing needs of the con- 
ceptus, and that the decline in plasma glucose is the result of increase in the apparent glucose distribution space. The glucose production rate in the GDM subjects who were also obese had increased by $10 \%$. Their systemic glucose production rates, however, were not higher than those in normal pregnant subjects, which suggests that the early decompensation in diabetes is the inability to assimilate an exogenous glucose load.

Sources of fuels for human fetus at term gestation. The rapid diffusion of glucose across the placenta in humans and animals has been described before (31-34). A gradient along which transfer of glucose occurs has been demonstrated previously and in this study. However, the fetal contribution to fetal glucose has not been evaluated in humans so far. During late pregnancy in rats infused with tracer $\left[\mathrm{U}-{ }^{14} \mathrm{C}\right]$ glucose, Goodner and Thompson (22) and Bossi and Greenberg (23) showed that the fetal plasma glucose specific activity was always lower than the maternal plasma glucose specific activity. These data would suggest that a fetal glucose source, in addition to maternal glucose diffusing across the placenta, was contributing to the fetal plasma glucose. Furthermore, the rat fetus could increase glucose production in utero and thus maintain plasma glucose concentration when the mother was made hypoglycemic by insulin (35), or during prolonged maternal fasting (36). The fetal maintenance of glucose homeostatis during glucose deprivation from the mother has been attributed to fetal hepatic gluconeogenesis rather than glycogenolysis by the studies of Goodner et al. (35) and Girard et al. (36). These studies demonstrated minimal change in hepatic glycogen phosphorylase and increase in activities of gluconeogenic enzyme phosphoenol pyruvate carboxykinase in the fetus. Such studies on the human fetus have not been possible.

Early in gestation, the isolated, human fetal liver can release glucose in response to aglycemia (37). A similar response has been shown in isolated monkey liver preparation near term gestation (38). Furthermore, the human fetal liver has the necessary enzymes for gluconeogenesis, and the fetal liver explant can incorporate $\left[{ }^{14} \mathrm{C}\right]$ alanine into glucose $(39,40)$. In the present investigation, we evaluated whether the human fetus of a normal mother or a metabolically controlled GDM or IDM mother initiates glucose production in utero before delivery. A comparison of ${ }^{13} \mathrm{C}$ enrichment of maternal and fetal glucose during unenriched steady state (Fig. 3) and enriched steady state (Fig. 2) shows that the fetus of a mother undergoing elective caesarean section at term gestation with uninitiated labor does not produce glucose in utero. Whether labor and delivery with associated vascular adjustment initiate glucose production is not known. After birth, however, the newborn infant does maintain a normal blood glucose concentration and establishes a systemic glucose production rate of $4.5 \mathrm{mg} / \mathrm{kg} \cdot \mathrm{min}$ by
$2 \mathrm{~h}$ of age (13). In three out of five GDM mothers receiving $\left[1-{ }^{13} \mathrm{C}\right]$ glucose, the $\mathrm{CA} \delta^{13} \mathrm{C}$ were significantly lower than that of the mother. The fourth one, with the highest blood glucose $(100 \mathrm{mg} / 100 \mathrm{ml})$, had similar $\delta^{13} \mathrm{C}$ in CA and CV. Thus, intermittent hyperglycemia and normoglycemia may have initiated glucose production in these infants.

As has been shown by others, the betahydroxybutyrate concentration in maternal and cord blood followed a pattern which suggested a simple diffusion from the mother to the fetus (41-43). The fetal capacity to use ketones for oxidation has been evaluated in both human and animal species. The fetus can use ketones derived from the mother as alternate fuels for oxidation in situations of glucose privation.

In summary, commensurate with the increasing demands, the systemic glucose production rate in pregnancy is increased. The increased glucose production rate is seen in the presence of a lowered plasma glucose concentration. The latter may be the result of an increase in the apparent distribution space of glucose. The maternal responses to fasting are accelerated in that there is a more rapid decline in blood glucose and rapid lipolysis. Finally, a brief maternal fast before an elective caesarean section does not initiate fetal glucose production in normal or diabetic subjects.

\section{ACKNOWLEDGMENTS}

The authors gratefully acknowledge the technical assistance of Mr. George T. Campbell, Ms. Gina Ma, and Ms. Margaret Wilson; and the secretarial help of Ms. Jayne Subwick.

This study was supported by a grant from the Diabetes Association of Greater Cleveland, grants HD 05740 and HD 11089 from the National Institute of Child Health and Human Development, grants OCE 75-20431-A01 and OCE 76-01457 from the Submarine Geology and Geophysics Program of the National Science Foundation, and grant 5701-RR00120-12 from the Perinatal General Research Center of Division of Research Facilities.

\section{REFERENCES}

1. Freinkel, N., B. E. Metzger, M. Nitzan, J. W. Hare, G. E. Shambaugh, R. T. Marshall, B. Z. Surmaczynska, and T. C. Nagel. 1972. "Accelerated starvation" and mechanisms for the conservation of maternal nitrogen during pregnancy. Isr. J. Med. Sci. 8: 426-439.

2. Felig, P. 1973. Maternal and fetal fuel homeostasis in human pregnancy. Am. J. Clin. Nutr. 26: 998-1005.

3. Kim, Y. J., and P. Felig. 1972. Maternal and amniotic fluid substrate levels during caloric deprivation in human pregnancy. Metab. Clin. Exp. 21: 507-512.

4. Felig, P., Y. J. Kim, V. Lynch, and R. Hendler. 1972. Amino acid metabolism during starvation in human pregnancy. J. Clin. Invest. 51: 1195-1202.

5. Freinkel, N., and B. E. Metzger. 1975. Some considerations of fuel economy in the fed state during late human pregnancy. In Early Diabetes in Early Life. Rafael A. Camerini-Devalos and Harold S. Cole, editors. Academic Press Inc., New York. 289-301. 
6. Metzger, B. E., J. W. Hare, and N. Freinkel. 1971. Carbohydrate metabolism in pregnancy IX: Plasma levels of gluconeogenic fuels during fasting in the rat. J. Clin. Endocrinol. Metab. 33: 869-872.

7. Herrera, E., R. H. Knopp, and N. Freinkel. 1969. Carbohydrate metabolism in pregnancy. VI. Plasma fuels, insulin, liver composition, gluconeogenesis, and nitrogen metabolism during late gestation in the fed and fasted rat. J. Clin. Invest. 48: 2260-2272.

8. Metzger, B. E., F. S. Agnoli, and N. Freinkel. 1970. Effect of sex and pregnancy on formation of urea and ammonia during gluconeogenesis in the perfused rat liver. Horm. Metab. Res. 2: 367-368.

9. Metzger, B. E., F. S. Agnoli. J. W. Hare, and N. Freinkel. 1973. Carbohydrate metabolism in pregnancy. X. Metabolic disposition of alanine by the perfused liver of the fasting pregnant rat. Diabetes. 22: 601-612.

10. Steele, R., J. S. Wall, R. C. DeBodo, and N. Altszuler. 1956. Measurement of size and turnover rate of body glucose pool by isotope dilution method. Am. J. Physiol. 187: 15-24.

11. Smith, B. N. 1972. Natural abundance of the stable isotopes of carbon in biological systems. BioScience 22: 226-231.

12. DeNiro, M. J., and S. Epstein. 1977. Mechanism of carbon isotope fractionation associated with lipid synthesis. Science (Wash. D. C.). 197: 261-263.

13. Kalhan, S. C., S. M. Savin, and P. A. J. Adam. 1976. Measurement of glucose turnover in the human newborn with glucose-1-13 C. J. Clin. Endocrinol. Metab. 43: 704-707.

14. Kalhan, S. C., S. M. Savin, and P. A. J. Adam. 1977. Estimation of glucose turnover using stable tracer glucose- $1{ }^{13} \mathrm{C}$. J. Lab. Clin. Med. 89: 285-294.

15. Craig, H. 1957. Isotopic standards for carbon and oxygen and correction factors for mass-spectrometric analysis of carbon dioxide.Geochim. Cosmochim. Acta. 12: 133-149.

16. Craig, H. 1953. The geochemistry of the stable carbon isotopes. Geochim. Cosmochim. Acta. 3: 53-92.

17. Persson, B. 1969. Determination of plasma acetoacetate and $D$ - $\beta$-Hydroxybutyrate in newborn infants by an enzymatic fluorometric micro-method. Scand. J. Clin. Lab. Invest. 25: 9-18.

18. Herbert, V., K. S. Lau, C. W. Gottlied, and S. J. Bleicher. 1965. Coated charcoal immunoassay of insulin. J. Clin. Endocrinol. Metab. 25: 1375-1384.

19. Victor, A. 1974. Normal blood sugar variation during pregnancy. Acta Obstet. Gynecol. Scand. 53: 37-40.

20. Reichard, G. A., N. F. Moury, N. J. Hochella, A. L. Patterson, and S. Weinhouse. 1963. Quantitative estimation of the Cori cycle in the human. J. Biol. Chem. 238: 495-501.

21. Hostetler, K. Y., H. R. Williams, W. W. Shreeve, B. R. Landau. 1969. Conversion of specifically ${ }^{14} \mathrm{C}$-labelled lactate and pyruvate to glucose in man. J. Biol. Chem. 244: 2075-2077.

22. Goodner, C. J., and D. J. Thompson. 1967. Glucose metabolism in the fetus in utero: The effect of maternal fasting and glucose loading in the rat. Pediatr. Res. 1: 443-451.

23. Bossi, E., and R. E. Greenberg. 1972. Sources of blood glucose in the rat fetus. Pediatr. Res. 6: 765-772.

24. Felig, P. 1977. Body fuel metabolism and diabetes mellitus in pregnancy. Med. Clin. N. Am. 61: 43-66.

25. Metzger, B. E., and N. Freinkel. 1975. Regulation of maternal protein metabolism and gluconeogenesis in the fasted state. In Early Diabetes in Early Life. Rafael A. Camerini-Devalos and Harold S. Cole, editors, Academic Press, Inc., New York. 303-311.
26. Wise, J. K., S. S. Lyall, R. Hendler, and P. Felig. 1973. Evidence of stimulation of glucogon secretion by alanine in the human fetus at term. J. Clin. Endocrinol. Metab. 37: 345-348.

27. Kalhan, S. C., S. M. Savin, and P. A. J. Adam. 1977. Attenuated glucose production rate in newborn infants of insulin-dependent diabetic mothers. N. Engl.J. Med. 296: 375-376.

28. Bier, D. M., R. D. Leake, M. W. Haymond, K. J. Arnold, L. D. Gruenke, M. A. Sperling, and D. M. Kipnis. 1977. Measurement of "true" glucose production rates in infancy and childhood with 6,6-dideuteroglucose. Diabetes. 26: 1016-1023.

29. Metzger, B. E., J. W. Hare, E. Hinsdale, and N. Freinkel. 1974. Glucose kinetics and the role of insulin during the hypoglycemia of fasting in late pregnancy. Diabetes. 23: 342. (Abstr.)

30. Bleicher, S. J., J. B. O'Sullivan, and N. Freinkel. 1964. Carbohydrate metabolism in pregnancy. V. The interrelations of glucose, insulin and free fatty acids in late pregnancy and post partum. N. Engl. J. Med. 271: 866-872.

31. Holmberg, N. G., B. Kaplan, M. J. Karvonen, J. Lind, and M. Malm. 1956. Permeability of human placenta to glucose, fructose, and xylose. Acta. Physiol. Scand. 36: 291-299.

32. Young, M. 1975. Placental transfer of glucose and amino acids. In Early Diabetes in Early Life. R. A. CameriniDanalos and H. S. Cole, editors. Academic Press, Inc., New York. 237-242.

33. Folkart, G. R., J. Dancis, W. L. Money. 1960. Transfer of carbohydrates across guinea pig placenta. Am.J. Obstet. Gynecol. 80: 221-223.

34. Karvonen, M. J., and N. Raiha. 1954. Permeability of placenta of the guinea pig to glucose and fructose. Acta Physiol. Scand. 31: 194-202.

35. Goodner, C. J., M. J. Conway, and J. H. Werbach. 1969. Relation between plasma glucose levels of mother and fetus during maternal hyperglycemia, hypoglycemia, and fasting in the rat. Pediatr. Res. 3: 121-127.

36. Girard, J. R., P. Ferre, M. Gilbert, A. Kervran, R. Assan, and E. B. Marliss. 1976. Stimulation of fetal gluconeogenesis in utero by maternal fasting near term in the rat. Clin. Res. 24: 361A. (Abstr.)

37. Adam, P. A. J., A. L. Schwartz, E-L. Rahiala, and M. Kekomaki. 1978. Glucose production in midterm human fetus. I. Autoregulation of glucose uptake. Am. J. Physiol. 234: E560-E570.

38. Glinsmann, W. H., H. J. Eisen, A. Lynch, and R. A. Chez. 1975. Glucose regulation by isolated near term fetal monkey liver. Pediatr. Res. 9: 600-604.

39. Raiha, N. C. R., and K. O. Lindros. 1969. Development of some enzymes involved in gluconeogenesis in human liver. Ann. Med. Exp. Biol. Fenn. 47: 146-150.

40. Schwartz, A. L., and T. W. Rall. 1975. Hormonal regulation of incorporation of alanine- ${ }^{14} \mathrm{C}$ into glucose in human fetal liver explants. Diabetes. 24: 650-657.

41. Scow, R. O., S. S. Chernick, and B. B. Smith. 1951. Ketosis in the rat fetus. Proc. Soc. Exp. Biol. Med. 98: 833-835.

42. Paterson, P., J. Sheath, P. Taft, and C. Wood. 1967. Maternal and fetal ketone concentrations in plasma and urine. Lancet. I: 862-865.

43. Sabata, V., H. Wolf, and S. Lausmann. 1968. The role of free fatty acids, glycerol, ketone bodies and glucose in the energy metabolish of the mother and fetus during delivery. Biol. Neonatorum. 13: 7-17. 